\title{
Experimental and Theoretical Study of Fragment Safety Distance of Fragmenting Munitions
}

\author{
H.N. Behera ${ }^{1,2}$, Sarbjit Singh ${ }^{2}$, Pal Dinesh Kumar ${ }^{2}$, Asha Gupta ${ }^{1}$ \\ ${ }^{1}$ Panjab Engineering College (Deemed to be University), Sector 10, Chandigarh, India \\ ${ }^{2}$ Terminal Ballistics Research Laboratory (TBRL-DRDO), Sector-30, Chandigarh 160030, India \\ hullash334@gmail.com, sarb59@gmail.com, ashagoel30@yahoo.co.in
}

Keywords: Fragment Safety Distance, Controlled Fragmentation, Fragment velocity, High Strain Rate

\begin{abstract}
The fragment safety distance is an important requirement for test and evaluation of the munition stores in the field trials. It determines the area to be cleared or evacuated before conduct of any trial activity. In this paper, theoretical and experimental work is carried out for establishing the explosive parameters and its interaction with the metallic casing. High explosives are used for controlled fragmentation to generate specific-size-and-weight fragments with lower velocity. Empirical relationship based on high strain rate and Gurney energy criteria were applied and optimized. Two prototypes having two different type explosive filling were fabricated to generate the fragment data. This enables to determine the safety distance useful for conducting trials in small ranges with required safety. The experimental data reveals that $90 \%$ fragments of a definite shape and size have been generated. The recorded fragment velocity was of the order of 250 to $400 \mathrm{~m} / \mathrm{s}$. Based on these data, safety distance was calculated and found to be about $400 \mathrm{~m}$. Experimentally, fragments were recovered and found up to $130 \mathrm{~m}$ from the point of burst.
\end{abstract}

\section{Introduction}

The objective of reducing fragment safety distance is to use the smaller ranges for trial and performance evaluation of fragmenting munitions. Fragment safety distance is a function of fragment mass, fragment velocity and fragments' aerodynamic behavior. If we can lower the fragment velocity and control fragment shape and size, then it is possible to reduce the fragment safety distance significantly. To do this, attempts are made to replace high explosive by high explosives for lower fragment velocity and controlled fragmentation technique [1-2] for definite shape fragment with known ballistic behaviors.

\section{Theoretical Work}

\subsection{Particle Velocity and Maximum Pressure of the Shock Wave}

The reduced pressure of the explosive filling inside the steel cylindrical warhead is calculated using Hugoniot values of various explosives, paraffin/High Energy Substitute (HES) and steel materials. The values [3] are given in Figure 1. The following equations are used for particle velocity and maximum pressure acting on the steel casing.

$$
\begin{aligned}
& P_{C J}=\rho_{0} u_{J C} D \\
& P=\rho_{0} C_{0} u+\rho_{0} s u^{2} \\
& P=\left(2.412 \mathrm{P}_{C J}\right)-\left(1.7315 P_{C J} / u_{C J}\right) u+\left(0.3195 P_{C J} / u_{C J}^{2}\right) u^{2}
\end{aligned}
$$

Where $\mathrm{D}=$ detonation velocity, $\mathrm{P}_{\mathrm{cj}}=\mathrm{CJ}$ Pressure, $\mathrm{u}=$ particle velocity, $\mathrm{P}=$ pressure 
The equations 1- 3 are solved for particle velocity u and maximum pressure $\mathrm{P}$ of the shockwave.

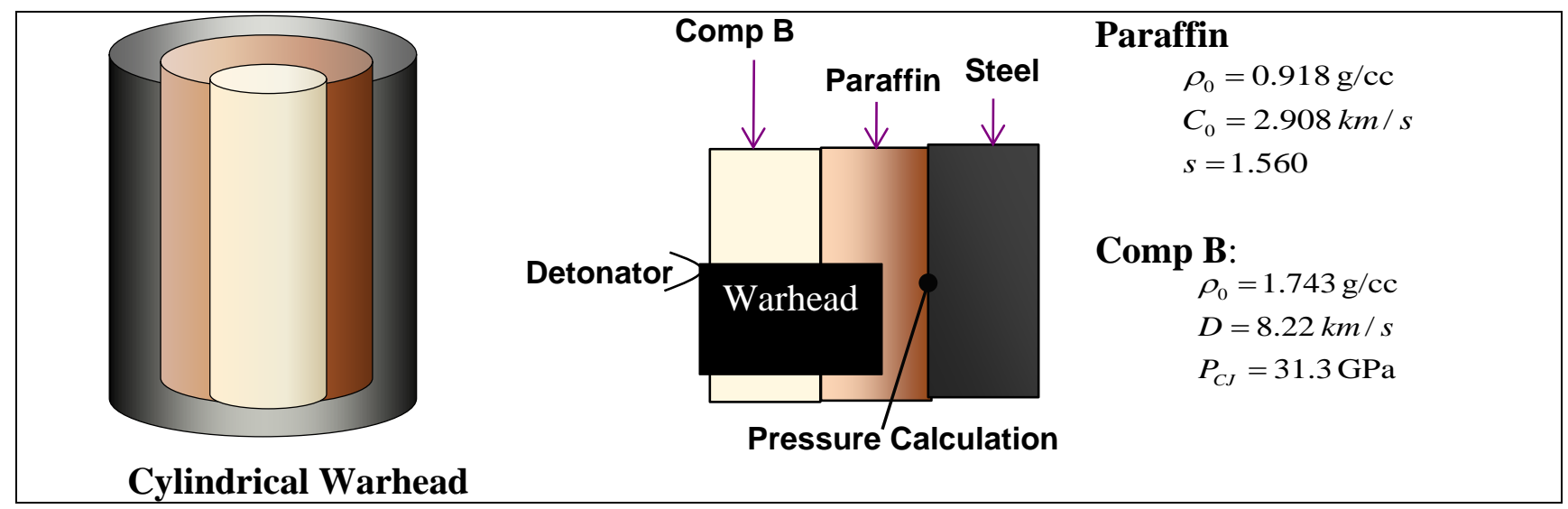

Figure 1 Pressure Calculation

\subsection{Modified Gurney Formula for Initial Fragment Velocity}

The initial fragment velocity is calculated using the Gurney equation [4]. But the Modified Gurney equation is also used to accommodate the ratio of warhead length to its internal diameter. The initial velocity of fragments resulting from a high-order detonation of a cylindrical warhead expressed as

$$
\mathrm{V}_{0}=\sqrt{2 \mathrm{E}} \sqrt{\frac{\mathrm{C} / \mathrm{M}}{\left(1+\frac{0.5 \mathrm{C}}{\mathrm{M}}\right)\left(1+\frac{0.5 \mathrm{Di}}{\mathrm{L}}\right)}}
$$

Where

$\mathrm{V}_{\mathrm{o}}=$ Initial velocity of fragments $(\mathrm{m} / \mathrm{s}), \sqrt{ }(2 \mathrm{E})=$ Gurney Constant $(\mathrm{m} / \mathrm{s})$

$\mathrm{C}=$ Charge mass $(\mathrm{g}), \mathrm{M}=$ casing mass $(\mathrm{g}), \mathrm{L}=$ warhead length $(\mathrm{mm}), \mathrm{Di}=$ internal diameter $(\mathrm{mm})$

\subsection{Fragment Trajectory}

The point mass trajectory model is used to compute the trajectory of a fragment with constant mass [5-6]. The fragment in air experiences the aerodynamic drag force and gravity. The motion of the fragment is described by the following differential equations:

$$
\begin{gathered}
\dot{V}_{x}=-\frac{\rho A_{p} C_{d}}{2 m} V V_{x} \\
\dot{V}_{y}=-\frac{\rho A_{p} C_{d}}{2 m} V V_{y}-g \\
\dot{V}_{z}=-\frac{\rho A_{p} C_{d}}{2 m} V V_{z}
\end{gathered}
$$

Where

$\mathrm{m}=$ fragment mass(g), $\mathrm{V}=$ magnitude of velocity vector $(\mathrm{m} / \mathrm{s}), \mathrm{V}_{\mathrm{x}}, \mathrm{V}_{\mathrm{y}} \mathrm{V}_{\mathrm{z}}=$ components of velocity of fragments, $g=$ gravitational acceleration $\left(\mathrm{m} / \mathrm{s}^{2}\right), \quad \rho=$ air $\operatorname{density}(\mathrm{g} / \mathrm{cc}), \quad \mathrm{Cd}=\mathrm{drag}$ coefficient of fragment,Ap=presented area of fragment $\left(\mathrm{mm}^{2}\right)$. 


\section{Experimental Work}

Based on the theoratical calculations, two prototypes of $3 \mathrm{~kg}$ class controlled fragmentation warhead having two different type explosive filling were fabricated to generate the fragment data. Both prototypes were subject to static trial under similar conditions. Velocity measurement system was used to record the fragment velocity and strawboards for fragment recovery. The survey method was used to trace the fragments up to $250 \mathrm{~m}$ distance from the point of burst. The trial setup is shown in Figure 2.

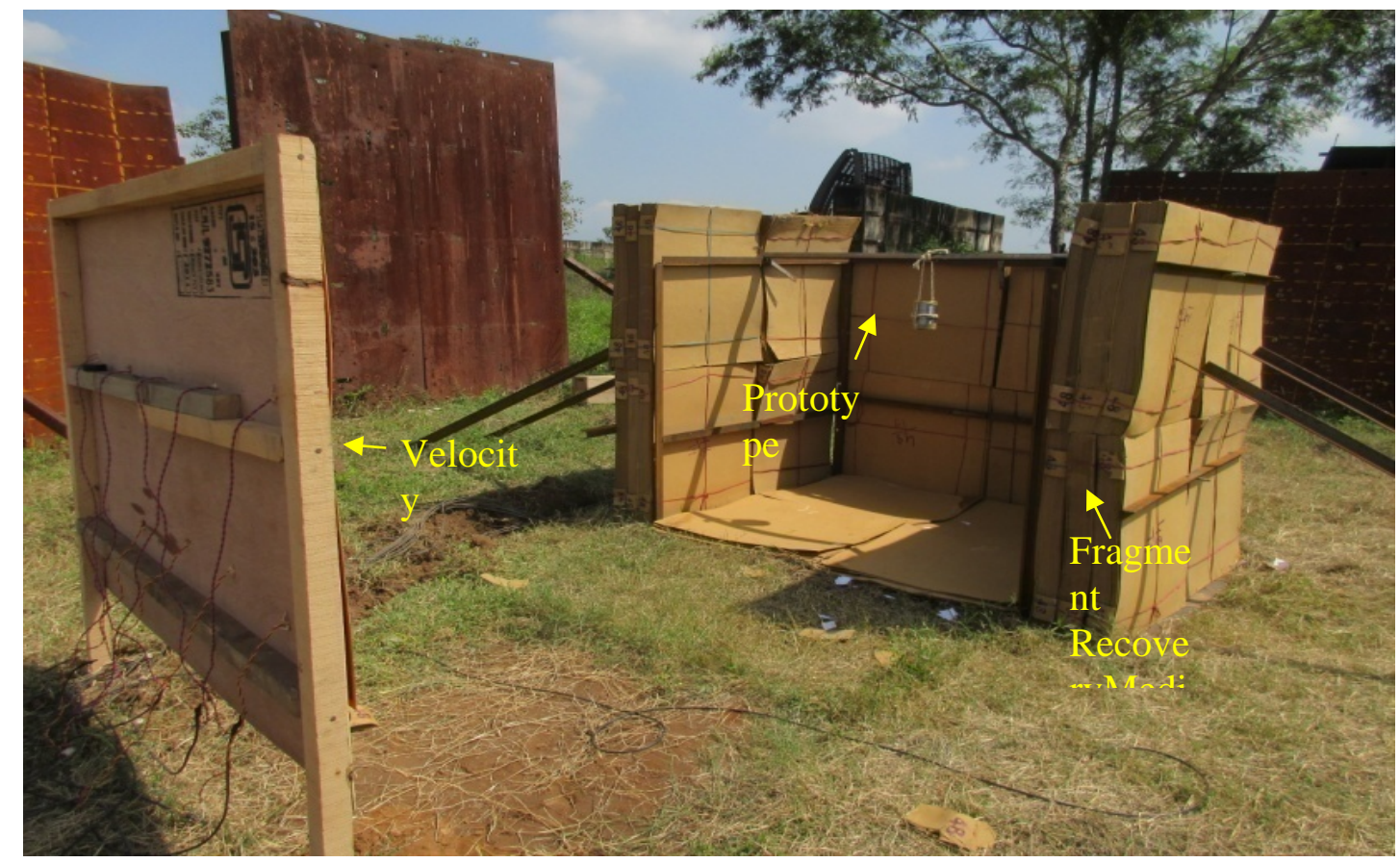

Figure 2 Trial Setup

\section{Result \& Analysis}

Based on pressure and initial velocity of fragments, different ratios of diameters of high explosive substitute to that of high explosive were calculated. 


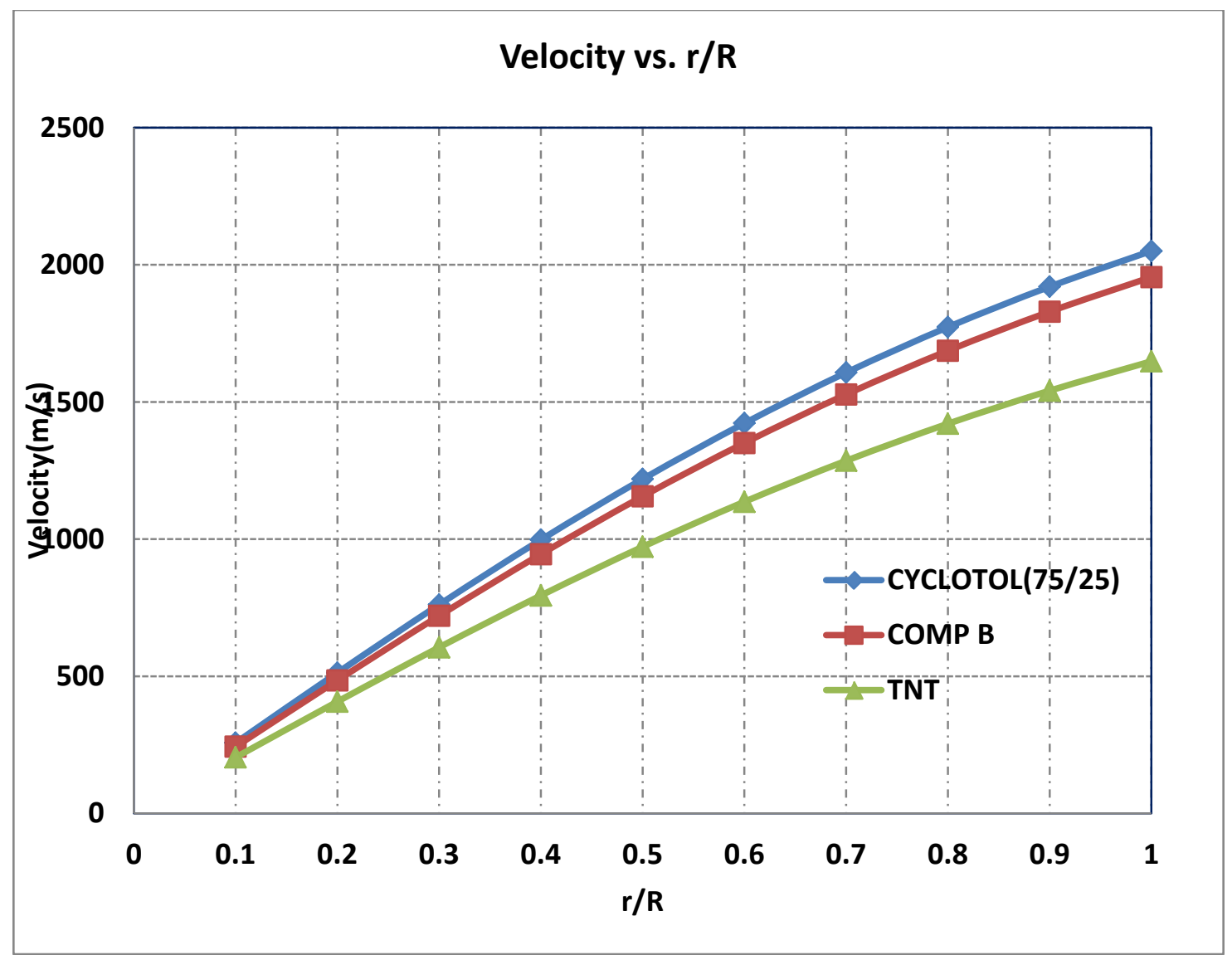

Figure 3. Fragment Velocity vs Filling Pattern

In Figure 3.The Curves are plotted using reduced pressure for different combinations of ratios of three explosive with HES paraffin. The curve of Fragment velocity vs different ratios of three explosive to HES are used to compute the optimum ratios for lower the fragment velocity. As an example, the composition(TNT:HES) gives the fragment velocity up to $600 \mathrm{~m} / \mathrm{s}$.

Based on these calculations, prototypes was fabricated and tested. Experimentally generated fragments are shown in Figure 4.

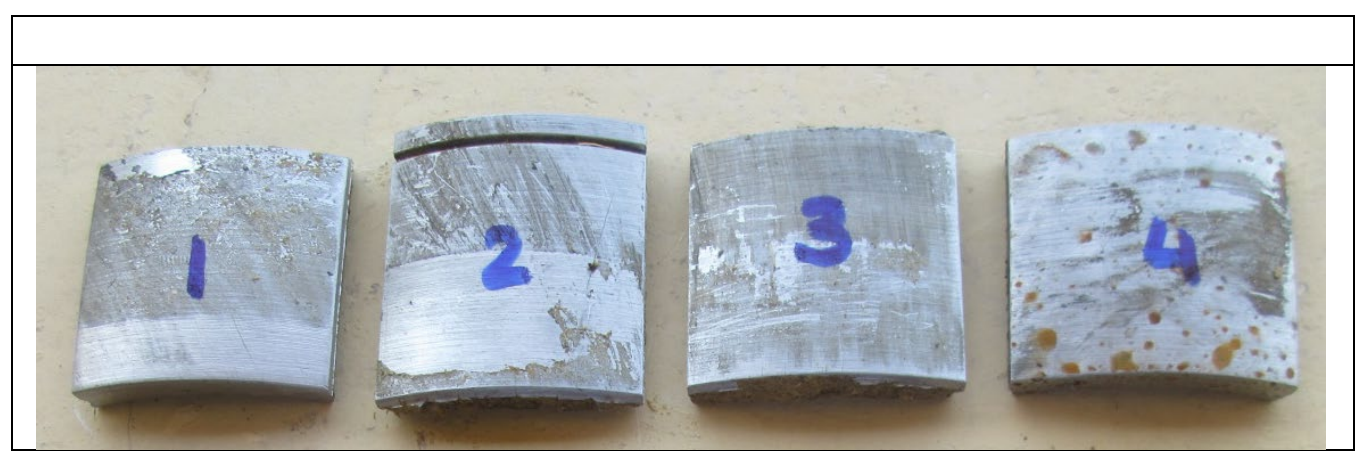

Figure 4. 3-kg class Prototype Warhead and Fragments 
Using the fragment trajectory equations, fragments with highest velocity and diferent orientations were used to compute the fragment safety distances. The computed safety distance is about $400 \mathrm{~m}$. The survey method was used to find the trace of fragments on the ground. Experimentally, it was observed that the fragments travelled up to $130 \mathrm{~m}$.

\section{Conclusions}

Two prototypes having two different type explosive filling were fabricated to generate the fragment data. This enables to determine the safety distance useful for conducting trials in small ranges with required safety. The experimental data reveals that $90 \%$ fragments of a definite shape and size have been generated. The fragment velocity is recorded in the order 250 to $400 \mathrm{~m} / \mathrm{s}$. Based on these data, safety distance was computed. The calculation shows that maximum safety distance is about $400 \mathrm{~m}$. The experimetal observation shows that fragments travelled upto $130 \mathrm{~m}$.

\section{Acknowledgements}

The authors would like to gratefully thank Dr. Manjit Singh, DS and Director TBRL for his support and encouragement for this research work. The authors are also very thankful to all the supporting trial team members. This research did not receive any specific grant from any funding agencies in the public, commercial, or not-for-profit sectors.

\section{References}

[1] W Arnold, “Controlled Fragmentation”, Shock Compression Matter,2001

[2] D Villano and F Galliccia “Innovative Technologies for Controlled Fragmentation Warheads”,27th International Symposium on Ballistics,Freiburg,Germany,2013. https://doi.org/10.1115/1.4023341

[3] R. M. Lloyd, “Conventional Warhead System and Engineering Design”, Progress in Astronautics and Aeronautics, Volume 179.1991

[4] R. W. Gurney, “The Initial Velocities of Fragments from Bombs, Shells and Grenades” BRL Report No 405, 1943. https://doi.org/10.1115/1.4023341

[5] Robert L McCoy, "Modern Exterior Ballistics - the Launch and Flight Dynamics of Symmetric Projectiles”, 1999

[6] F.McCleskey., “Drag Co-efficients for Irregular Fragments,”, NSWC TR 87-89,Naval Surface Warfare Centre, Dahlgreen, Virginia, February 1998 
